See Article page 395.

\section{Commentary: Up, down, right, left: Addressing the shortage of donor lungs for transplantation}

\author{
Elliot Wakeam, MD, MPH, and \\ Andrew C. Chang, MD
}

Worldwide, donor lungs for lung transplantation remain in short supply. In no country is this shortage as acute as it is in Japan, where donation rates remain low due to cultural and other factors. As a result, Japanese lung transplant surgeons are renown for their creativity and technical prowess in addressing this shortage. Chida and colleagues ${ }^{1}$ from Dokkyo Medical University School of Medicine detail their technique of right-to-left inverted single lung transplantation-an extension of the work that has been done in Japan to pioneer living donor lung transplantation and other techniques to address the donor shortage. They should be commended for describing this complex, technical operation.

In North America, the reasons for donor lung shortages are not related to a low rate of donation, but rather to a low rate of use by surgeons of potentially eligible donor lungs. In the United States especially, where the majority of lung transplantation is done in relatively low-volume centers, many useable donor lungs are discarded. Several reports have confirmed that decline of lungs for quality or other reasons on the US donor list does not indicate that lungs are not usable, in fact Cypel and colleagues ${ }^{2}$ from the Toronto Lung Transplant Program have detailed their experience using lungs declined across the United States and found no difference in outcomes of these versus standard donor lungs from Canada. Other reports have shown that regardless of where a lung is accepted on the US match run list, the outcomes do not differ, implying that declines at the top of the list are not reliable markers of organ quality. ${ }^{3}$

From the Section of Thoracic Surgery, University of Michigan, Ann Arbor, Mich Disclosures: The authors reported no conflicts of interest.

The Journal policy requires editors and reviewers to disclose conflicts of interest and to decline handling or reviewing manuscripts for which they may have a conflict of interest. The editors and reviewers of this article have no conflicts of interest.

Received for publication Aug 26, 2020; revisions received Aug 26, 2020; accepted for publication Aug 28, 2020; available ahead of print Sept 15, 2020.

Address for reprints: Elliot Wakeam, MD, MPH, Section of Thoracic Surgery, University of Michigan, 1500 E Medical Center Dr, Ann Arbor MI 48109-5344 (E-mail: ewakeam@med.umich.edu).

JTCVS Techniques 2020;4:398

2666-2507

Copyright $@ 2020$ The Authors. Published by Elsevier Inc. on behalf of The American Association for Thoracic Surgery. This is an open access article under the CC BY-NCND license (http://creativecommons.org/licenses/by-nc-nd/4.0/).

https://doi.org/10.1016/j.xjtc.2020.08.066

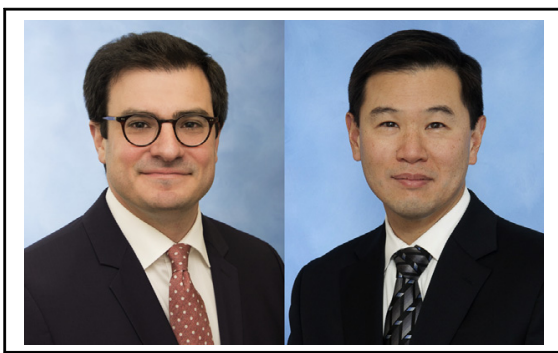

Elliot Wakeam, MD, MPH (left), and Andrew C. Chang, MD (right)

CENTRAL MESSAGE

Although an innovative approach

to extending the use of donor

lungs is described, continued ef-

forts to improve overall donation

rate should be pursued.

The reasons for this are myriad, and include lack of specialized training in lung transplant, little experience with salvage techniques for marginal donors such as extracorporeal membrane oxygenation, and others, but certainly an unwillingness to take on risk because of the implications for United Network for Organ Sharing reporting and regulatory backlash also play a role.

The report from Chida and colleagues ${ }^{1}$ is an impressive technical feat, and the authors should be congratulated on the successful implementation of this technique. However, given the relative number of donors and recipients in the United States, the applicability of a complex technique is questionable in this country, when simply making the decision to use a greater number of standard donors would suffice. Changing our decision making en masse is no easy feat, and would require a concerted effort from national policy makers to encourage greater use of donor organs in centers of excellence. If we could stop turning down so many lungs, we could use them up-and we would not need to flip them from right to left.

\section{References}

1. Chida M, Araki O, Karube Y, Maeda S. Right-to-left inverted single lung transplantation. J Thorac Cardiovasc Surg Tech. 2020;4:395-7.

2. Cypel M. Outcomes of lung transplantation at a Canadian center using donors from the United States. Presented at: the 100th Annual Meeting of The American Association for Thoracic Surgery:A Virtual Learning Experience; May 22-23, 2020.

3. Singh E, Schecter M, Towe C, Rizwan R, Roosevelt B, Tweddell J, et al. Sequence of refusals for donor quality, organ utilization, and survival after lung transplantation. J Heart Lung Transplant. 2019;38:35-42. 